\title{
Not So Silent: How Social Support is Given and Received in Dealing with Sexual Harassment in Sri Lankan Work-Places
}

\author{
Arosha S. Adikaram
}

\begin{abstract}
The aim of this paper is to explore how silence, secrecy and censorship related to sexual harassment are fragmented through dialogue and information sharing among social networks, leading to different types of social support given and received. In-depth interviews with 40 respondents and focus group discussions with four groups were carried out under the qualitative research approach. The theory of social support was employed as the theoretical basis of the study. The findings indicated that through dialogue and information sharing related to sexual harassment within social networks of friends, family, co-workers and sometimes superiors, women gain and give emotional, informational, instrumental and appraisal support, emphasizing the many instances when the issue becomes open, non-privatized, and social. Stemming from these findings, implications for managers in terms of using social support as a means of dealing with sexual harassment in organizations are discussed.
\end{abstract}

Keywords: silence, sexual harassment, social networks, social support, Sri Lanka.

\section{Introduction}

Even after decades of intensive research, rigorous public debate and extensive interventions, sexual harassment continues to persist at workplaces. Sri Lanka, being the first Asian country to address the issue through government legislation, considers sexual harassment to be a criminal offence under the Penal Code (Amendment) No. 22 of 1995, where sexual harassment is defined as:

Arosha S Adikarm, $\boldsymbol{P h D}$ is a Senior Lecturer, Department of Human Resource Management, Faculty of Management and Finance, University of Colombo. E-mail: arosha@hrm.cmb.ac.lk 
Not So Silent: How Social Support is Given and Received in Dealing with Sexual Harassment in Sri Lankan Work-Places

...Whoever, by assault or use of criminal force, sexually harasses another person by the use of words or actions, causes sexual annoyance or harassment to such other persons, commits the offence of sexual harassment...

The Act further states that

...Unwelcome sexual advances by words or actions used by a person in authority in a work place, or any other place, shall constitute the offence of sexual harassment...

In addition to these legal interventions at a macro level, companies and various other institutions such as women's organizations too have taken various steps including introduction of guidelines, policies and procedures to address the issue. Yet, while sexual harassment is considered a serious social issue throughout the world and is addressed in the public domain through these various legislations, policies and procedures, the issue is also consistently treated as individual (Fitzgerald \& Ormerod 1993), personal or private (Weeks et al. 1986, Clair 1993) and surrounded by secrecy (Clair 1993, Fitzgerald \& Ormerod 1993).

There are conflicting prior findings indicating how victims are silent about their experiences on one hand, and how they seek support from social sources and networks such as friends, family and coworkers, breaking this silence on the other hand. Yet, little attention has been given to these non-formal methods of dealing with sexual harassment in research (McDonald, Graham \& Martin 2010). Similarly, prior research also highlights the importance of breaking this silence surrounding sexual harassment and the role of social support for it. As research highlight, lack of support not only leads to silence, but also to other negative consequences such as suicide (Wijayatilake \& Zachariya 2000). In this backdrop, I attempt to explore how this silence is broken by women at workplaces in instances of sexual harassment, and how they employ social networks to gain and give social support. For this purpose, I turn to the theory of social support, using it as the theoretical basis for understanding this intricate phenomenon.

In the following sections, I will first expound more on how and when silence, secrecy and censorship take place with regard to sexual harassment. Then I will provide an overview of the theory of social support setting the foundation for the analysis of findings and discussion. I will next explain the research approach employed and the data collection and analysis methods followed by the presentation of findings. Finally, the paper ends with the discussion and conclusion, limitations of the study, implications for managers and directions for further research. 


\section{NSBM Journal of Management}

Vol. 1, No. 2, July-December, 2015

\section{Silence, Secrecy and Censorship in Sexual Harassment}

The issue of secrecy and silence is identified to be central in sexual harassment and is manifested in various ways (Clair 1993, King 1995, Rudman, Borgida \& Robertson 1995, Peirce, Rosen \& Hiller 1997, McDonald et al. 2010). Certain cultures such as the Sri Lankan culture, expect women to be silent on matters of sexuality including sexual harassment, treating the issue a taboo (Tambiah 1996, Ng \& Othamn 2002, Sapana Pradhan-Malla 2005, Adikaram 2014, Adikaram In press). Women are conditioned to show sexual ignorance and innocence (Tambiah 1996, Adikaram 2014), whereby they do not talk about matters related to sex and sexuality in the open (Foucault 1990, Adikaram In press). As researchers indicate there exists a 'sexual silence' (Shupe et al. 2002) '...that makes it difficult to discuss sexual issues in public...' (Sigal et al. 2005, p. 211). Accoridng to Foucault (1990), open discussion about sexual matters and sexuality is forebidden, leading to women forcing upon themselves decency of expression and censoring of certain vocabulary. In this context, it is said that women suffer in silence, maintaining secrecy and not sharing their experiences even with friends, let alone the authorities (Wijeytilake \& Zachariya 2000, Ng \& Othamn 2002, Sapana Pradhan-Malla 2005, McDonald et al. 2010).

On the other hand, the very nature of the issue is said to promote secrecy and silence. It is shown how sexual harassment mainly takes place behind closed doors (Kirby 1995), or in secluded places out of the public eye, on one-to-one contexts without witnesses (McDonald et al. 2010), and operated through censorship (McDonald et al. 2010). Perpetrators also build and secure secrecy about their behaviours contributing to this silence surrounding the issue (Cense \& Brackenridge 2001, Marks, Mountjoy \& Marcus 2012).

At the same time, self-blame (De Judicibus \& McCabe 2001, Ng \& Othamn 2002) and victim-blame (Ng \& Othamn 2002, Diekmann et al. 2013, Jang \& Lee 2013,) would also render women silent about their experiences, believing that they brought the harassment upon themselves by the way they dressed or behaved (Reese \& Lindenberge 1997, Ng \& Othamn 2002, Adikaram 2014). 'Victims are ashamed or embarrassed about what happened to them and prefer to keep quiet about it, often also because they are afraid of being labelled as either 'loose' women or 'frigid' women who cannot take a joke' (Haspels et al. 2001, p. 36). Further, vulnerability, whether financial or positional, too can lead to silence among victims of sexual harassment. 'Lacking even minimal job security, temporary workers have a compelling economic interest in maintaining their silence in the face of harassment, rendering them both extremely vulnerable to sexual harassment and powerless to combat it' (Chamberlain et al. 2008, p. 267). 
Not So Silent: How Social Support is Given and Received in Dealing with Sexual Harassment in Sri Lankan Work-Places

Yet, conversely, a plethora of research also indicate how women seek social support, breaking this silence and secrecy by involving the family, friends or co-workers (Hotteling 1991, Gutek \& Koss 1993, Fitzgerald, Swan \& Fischer 1995, Schneider, Swan \& Fitzgerald, 1997, Wijayatilake \& Zachariya 2000, Haspels et al. 2001, McDonald 2012). Nevertheless these studies appear to only scratch the surface of the concept of social support as a means of handling and coping with sexual harassment (Hotteling 1991, Gutek \& Koss 1993, Fitzgerald, Swan, \& Fischer 1995, Haspels et al. 2001). Handy (2006) says ' ...women do far more than simply support other women who are suffering individual harassment. They may also respond collectively to both individually targeted and systemic harassment, developing a range of collective strategies for containing or eliminating unwelcome behaviour'. (p. 4). Yet, these different ways and means of gaining and giving support has not been sufficiently explored in previous studies.

At the same time, past research has also shown the many negative outcomes of social support and why women are reluctant to seek social support. It is said that when social support is sought, women are berated for their experiences of sexual harassment (Wijayatilake \& Zachariya 2000, Haspels et al. 2001) or conflicts arise with family members and friends (Skjorshammer \& Hofoss cited in Bowling \& Beehr 2006). Research also indicates how victims may not confide in co-workers, perceiving it as more risky, that they will not be believed, are advised not to take action (Bingham \& Scherer 1993), or fear the negative perceptions of others (Chaiyavej \& Morash 2009).

With these conflicting viewpoints, perceptions and findings, the aim of this paper is to explore how silence and secrecy related to sexual harassment is fragmented through social networks and social support and the different ways and means in which social support is provided for or obtained by women in different instances of sexual harassment. This knowledge will add to an insufficiently studied area in sexual harassment. Even though sexual harassment researchers have addressed social support received by victims in handling and coping with the issue, the concept of support has not been explored adequately or in depth. To my knowledge, there does not exist any research exploring this particular phenomena comprehensively. While studies on sexual harassment have used the term and the concept of social support, they have only vaguely addressed the issue (e.g. Cortina \& Wasti 2005, Bowling \& Beehr 2006, McDonald et al. 2012) without sufficiently indicating the different dimensions of social support, the different ways it is manifested and the outcomes of such social support related to sexual harassment. 


\section{NSBM Journal of Management}

Vol. 1, No. 2, July-December, 2015

Yet, with sexual harassment persisting in organizations even with numerous government, organizational and individual interventions, there is a need to investigate how social support can be employed to combat the issue. This is specially needed when there has been increased attention and effort to break this silence related to sexual harassment (Sapana Pradhan-Malla 2005). Further, the need for studies to explore conversation among women (and men) about their experiences and talks of sexual harassment too has been highlighted (Dougherty 1999). It is also said that in order to understand sexual harassment in all its complexity and to subsequently take appropriate and effective steps, management needs to understand how interactions and relationships at work contribute to sexual harassment.

\section{Theoretical Lens - Theory of Social Support}

Social support is founded within theories such as the social exchange theory, social comparison theory, and social competence theory (Langford et al. 1997). Social support is considered to be a multifaceted and complex concept with numerous definitions provided by researchers and theoreticians (Hupcey, 1998). Social support is commonly defined as '...the social resources that persons perceive to be available or that are actually provided to them by nonprofessionals in the context of both formal support groups and informal helping relationships...' (Gottlieb \& Bergen 2010, p. 512).

The concept is studied in different disciplines such as health, psychology (Leavy 1983, Cohen \& Wills 1985, Barrera 1986, Thoits 1986, Simoni, Frick \& Huang 2006, Heaphy \& Dutton 2008) and organizational studies (Brough \& Frame 2004, Heaphy \& Dutton 2008). Under organizational studies, social support has been commonly discussed in research related to international assignments (Copeland \& Norell 2002), job stress, work-life balance (Md-Sidin, Sambasivan, \& Ismail 2010) and job satisfaction (Brough \& Pears 2005). Social support is predominantly found to have a direct or indirect impact on stress or stressor-strain relationships (House 1981, Cohen \& Wills 1985, Lakey \& Cohen 2000, Beehr \& McGrath cited in Brough \& Frame 2004) and is identified to play a major role in alleviating occupational stress and health related problems (House 1981). Sexual harassment being identified as a source of stress and an issue of workplace health and well-being, the suitability of employing social support theory to understand the issue is clear.

Social support literature generally speaks about spouse/partner, children, other relatives, close friends, co-workers, supervisors, church, community or neighborhood, professionals or service providers and special groups as the sources of support (Cohen \& Wills 1985, Cooke et al. 1988, Wasti \& Cortina 2002, Brough \& Frame 2004, Cortina \& Wasti 2005, Bowling 
Not So Silent: How Social Support is Given and Received in Dealing with Sexual Harassment in Sri Lankan Work-Places

\& Beehr 2006). Further, different scholars have identified differnet types of social support (House 1981, Cooke et al. 1988). House (1981), one of the earliest writers on the concept, presents four types of supportive behaviours, which later scholars of social support have also commonly accepted. They are a) emotional support (involving caring, trust and empathy) b) instrumental support (involving helping others) c) informational support (involving providing information which can provide a solution to a problem), and d) apprasial support (involving information provided to help others to evaluate personal performance). In addition to these four, various researchers have suggested other types of social support such as esteem support and network support (Cooke et al. 1988). However, the current study employs the four types of support (emotional, instrumental, informational and appraisal support) presented by House (1981) in exploring the interactions and support women receive in cases of sexual harassment.

Being a complex discipline of study, social support research explores numerous areas such as sources of support, types of support provided, perceptions of support and social networks (Hupcey 1998). In this study, I concentrate on the sources of support and the types of support provided. Social support is also studied under different theoretical perspectives such as stress and coping perspective, social constructionist perspective and relationship perspective (Lakey \& Cohen 2000). I study the stress and coping perspective where it is said that social support reduces stressful life events through either the supportive actions of others or the belief that support is available (Lakey \& Cohen 2000). Even though antecedents of social support as well as consequences of social support have also gained attention in social support theory (Hupcey 1998, Langford et al. 1997), the current study focuses on social support only and does not delve deeper into antecedents (social networks, social embeddedness or social climate) nor the outcomes of social support such as health and psychological well-being of women.

\section{Methodology}

Information for this article was drawn from a study which explored how the meaning of the notion "sexual harassment at the workplace" was constructed using the constructivist grounded theory strategy of inquiry of Kathy Charmaz (2003, 2005). The respondents of the present article were 40 individuals, with whom in-depth, person-to-person interviews were carried out, and 22 respondents who participated in four focus group discussions consisting of four to five respondents each. The respondents of the in-depth interviews were selected using the purposive sampling technique at the initial coding stage and theoretical sampling during the selective coding stage of data collection and analysis (Charmaz 2003, 2005). 


\section{NSBM Journal of Management}

Vol. 1, No. 2, July-December, 2015

The respondents were approached using the snowball technique. They were all women 27 Sinhalese, seven Tamils and six Muslims. Thirty-three of the respondents were in the age group 20-35, while seven were above 35 years of age. Ten of the respondents were married and 30 respondents were unmarried. All the respondents hail from middle class families and hold clerical, executive or lower managerial level positions in their organizations.

The respondents of the focus group consisted of five married women and 17 unmarried women, 19 of whom were in the age group of 20-35 and three respondents above 35 years. Similar to the interview respondents, the focus group respondents too were from middle class families and hold clerical, executive or lower managerial level positions. Focus group respondents too were selected purposefully (Khan \& Manderson 1992), based on the preexisting social networks: friends or co-workers. This purposeful selection was done to specifically explore the social interaction, dialogue and information sharing that takes place among social networks. Focus groups were specifically useful in understanding and capturing how social support actually takes place in interactions within social networks.

An average of one and a half hours was spent on each in-depth interview and one hour was spent on each focus group discussion. The interviews and focus group discussions were transcribed verbatim and qualitatively analysed through a meticulous process of coding and categorizing using the social support theory constructs as the theoretical lens. Data analysis through initial coding started with the first few interviews and then subsequent selective coding and categorizing was carried out based on the analysis thus far. Priori codes based on the main types of support under social support theory were first identified (House 1981) and then these constructs were expounded through the other codes and categories, both inductive and priori.

\section{Findings}

In-depth interviews and focus group discussions provided ample evidence to show that even though generally sexual harassment is treated with secrecy and silence, women do talk about sexual harassment in public, in terms of their own experiences and experiences of others as well as about other aspects of sexual harassment such as possible perpetrators. Through the discussions that takes place within various social networks, information is shared and social support is given and received. Further, contrary to prior findings that the most common response to sexual harassment is ignorance and silence, the respondents of the study indicated numerous instances that they do engage in other assertive forms of reaction by seeking support and aid from social networks. Overall, the analysis expounded numerous instances, 
Not So Silent: How Social Support is Given and Received in Dealing with Sexual Harassment in Sri Lankan Work-Places

sources and ways social support occurs in cases of sexual harassment. These findings are analyzed and explained below under the main types of social support of House (1981).

\section{Emotional Support}

Support involving providing love, care, empathy and trust is known as 'emotional support' (House 1981). It was apparent that the respondents in the study generally discussed their experiences of sexually harassment with selected networks, seeking and giving empathy, caring and trust, and emotional support.

Respondents of two of the focus group discussions were close friends. Focus group 1 (FG 1) consisted of friends who were also working together in the same institution and focus group 2 (FG 2) consisted of friends who were working in different organizations. During these two focus group discussions it was apparent that many of the experiences of a sexual nature that they revealed to me were also known to each other, indicating they had discussed those experiences among themselves before. In many instances they reminded each other of the various experiences they had had.

FG 1:

Kimali: Yes. He (a perpetrator of sexually harassing behaviours) normally selects people from time to time to tell these things and to bestow his attention. Remember Mangala, how he used to single you out

Mangala: $\quad$ Yes, once he came often to my office room...

Sansala: $\quad$ That must have been very uncomfortable...

Kimali: $\quad$ And I asked Mangala 'why he is coming to meet you now'

Mangala: $\quad$ Yes, yes. 'You look very innocent and all'he would say.

Similar to the above discussion, there were a number of other instances where the respondents revived each other's memories, indicating their knowledge of each other's experiences. When asked, the respondents promptly agreed that they discussed these instances very regularly among friends. 
NSBM Journal of Management

Vol. 1, No. 2, July-December, 2015

FG 2

$\begin{array}{ll}\text { Interviewer: } & \text { Do you talk about these things among you all?... } \\ \text { Waruni and Thanu: } & \text { Yes, yes. } \\ \text { Thushari: } & \text { Always. } \\ \text { Hasini: } & \text { A lot. } \\ \text { Malka: } & \text { Definitely. }\end{array}$

However, it was seen that with emotional support, women appear to be more cautious and selective about whom they share the information with and hence they tend to confide mainly in close friends. Similar findings were seen in previous studies where it is said that the type and the nature of support will depend on the type of relationship; whether there are close relationships or casual acquaintances or whether the relationships are strong or weak (Gottlieb \& Bergen 2010).

FG 1
Interviewer: How do you talk about these among yourselves?
Mangala: $\quad$ Not with everybody
Kimali: $\quad$ Yes. Yes. Only us and some other friends...
Sharika: $\quad$ like...tell what happened. So that they can be careful...

The interactions and the support were different in the two other focus groups (FG $4 \& 5$ ), where the respondents were not all close friends. In these focus groups the respondents were peers working together (FG 4) and boarders sharing the same boarding house (FG 5), where the respondents were mainly just acquaintances. In these two focus group discussions they did not indicate any knowledge of other respondents' experiences or sharing of experiences as in FG 1 and 2.

As Dhammi (32 year old, married clerk in a financial institute) stated, women might be fearing that the information they share with others not so close to them can be used against them later on to harm them. Hence they only share certain information with close friends or people they deeply trust.

Another thing is...you shouldn't...this is a mistake a lot of ladies make...they tell others about their personal life. Whether it is to another female or a male, it is not good to say everything to others. It is ok to tell somebody very close 
Not So Silent: How Social Support is Given and Received in Dealing with Sexual Harassment in Sri Lankan Work-Places

and very trustworthy about your sorrows and all, but you shouldn't tell outside males or females those things. Without our knowing such things can affect us. Those are things that I learned.

Melani (32 year old, unmarried clerk working for a private organization) narrated an experience of a friend of hers, where the friend's boss had tried to force her into an affair. While Melani and her friend had had a good relationship where they generally share their experiences and problems, the friend has not shared this experience with Melani fearing being reprimanded by Melani.

I am the one who would always advise her. 'Don't do this don't do that' like that. So somehow, she didn't tell me about this incident fearing that I would scold her and it was only on the day that she left her place of work by getting a transfer that she told me. Then only she told me that the boss invited her like that. 'I didn't tell you fearing you would scold me or get into a fight,' she said.

Women are also said to not confide about their experiences with others, even with their family, due to fear of condemnation or criticism, fearing that others will think negatively of them (Haspels et al. 2001, Chaiyavej \& Morash 2009), fearing that they will not be believed (Bingham \& Scherer 1993) due to shame and/or fear (McDonald et al. 2010) or fearing that such sharing of information can lead to conflict with family members and friends (Skjorshammer \& Hofoss 1999, cited in Bowling \& Beehr 2006). The respondents in the current study also indicated similar reasons such as fear of reprisal and lack of trust for not sharing information and not seeking empathatic support in cases of sexual harassment from everybody they associate with. All in all, the respondents appeared to be very selective in sharing the most sensitive or personal experinces and in seeking empathetic support.

However, even if not close friends, females appear to share certain information about their experiences of a sexual nature and also about perpetrators of those behaviours, when there are very few females in the organization. For example, in several individual interviews which were conducted among females working in the same organization, it was revealed that they had shared information related to their experiences or perpetrators even though they were not very close friends like in FG 1 and FG 2. Dilani (38 years old and a Junior Executive Assistant) and Tharaka (22 year old, unmarried. trainee), work in a branch of a private bank where there are only about 4 females. Although they were not close friends, they indicated knowledge about each other's experiences of sexual harassment that had taken place in the bank. 


\section{NSBM Journal of Management}

Vol. 1, No. 2, July-December, 2015

Similarly, Tharanga (23 year old, unmarried, clerk) and Nadhini (27 years old, unmarried, executive) are also minority women workers in their branch who knew about each other's experiences although they too were not so close friends. Hence, while emotional support is intentionally sought from close friends, the information about instances of sexual harassment and related incidents is also shared (maybe not with the intention of gaining emotional support, but maybe with the intention of warning others) in certain instances with a few others (like other female co-workers who are a minority in a work setting). This might be due to the social security network they have or the feeling of kinship in these minority contexts.

More information about empathetic support given and received by friends indicated that overall it is mainly the female friends the respondents referred to in the matter of empathetic support in cases of sexual harassment; they said that they were always comfortable with female friends rather than male friends.

Aysha (25-year-old, unmarried, Muslim respondent working for a private educational institute):

I am more comfortable with female friends. And I share everything with them.

Similarly, stating how she does not trust male friends, Cathy (25 year old, unmarried Web designer working for an IT company) said,

The way I see it, men don't get close to you unless they want something. They can be close friends...I have many experiences like that... I know for sure.... It has happened to me. Even those very good friends, at least, will ask to start an affair with you after sometime.

This too indicates how trust plays a role in deciding from whom to seek support.

There were also a few instances where respondents had sought empathetic support from family members such as parents or husbands. Niranji (34-year-old married executive working for a financial institute) talked of how she shared an experience of a harassing nature with her husband, seeking empathetic support. A colleague at work had started talking to Niranji about his personal life and how he does not have a good relationship with his wife.

Then you feel that he is telling you all these because he wants something from you. He was a senior officer in the office. He was coming to me sort of with these talks and I told this to my husband and then told this person not to tell me those. It stopped after that. 
Not So Silent: How Social Support is Given and Received in Dealing with Sexual Harassment in Sri Lankan Work-Places

Here, Niranji does not appear to have wanted information support in the form of advice, or influential support in the form of the husband getting involved in settling the situation or appraisal support in affirming that the situation was sexual harassment. Rather, it appears that she had wanted empathetic understanding and emotional support as she did not mention about the husband getting involved in the situation other than to listen to her.

While the respondents did not mention specific instances where they had shared their experiences of sexual harassment with other family members, almost all the respondents stated how they shared everything with their mothers and many of them had mothers whom they treated as friends. As Prasanna (unmarried, 22-year-old banking assistant) said:

I am a girl ne...so there is a lot of things that I tell mother. Then mother would go and tell father.

Only Rupika (36 year- old married teacher working in a government school) and Samy (23 year-old Electronics Engineer working for an IT company) said how they always go to their father seeking help.

Rupika:

I generally confide in my father not my mother. Because mother always criticizes us. But father is not like that; he would listen to you and give you good advice without always criticizing.

Samy:

He has this easygoing personality.

In sum, it can be stated that respondents talk about and share their experiences of sexual harassment with social networks seeking and providing empathy, care and compassion. Respondents appear to be rather selective about with whom they share this information and mainly appear to consider close female friends, and in certain instances family members such as husbands, mothers and fathers, as their network of emotional support.

\section{Informational Support}

According to House (1981), informational support is the provision of information to a person, which the person can use in coping with personal and environmental problems. As House (1981) further emphasizes, this information is not in itself direct help provided as in the case of instrumental support, but rather it is the information that people can use to help 


\section{NSBM Journal of Management}

Vol. 1, No. 2, July-December, 2015

themselves. Similarly, respondents of the current study also engaged in giving and receiving informational support by sharing different information, advice and caution related to sexual harassment.

Respondents commonly shared with others their own experiences of sexually harassing behaviours and also about known flirts (office Romeos) in the organization and their behaviours, with the intention of advising and cautioning others. This sharing of information was mostly with friends, co-workers and in rare instances with family members. Looking at the type of information that respondents provide it is clear that this information is supportive of women in making decisions about whom to interact with, how to behave with others and how to be careful about certain people in the organization.

Malani, (42 year old unmarried clerk of a government corporation) stated how she provided informational support to her colleagues so that they could protect themselves from the same perpetrators.

Though I have faced incidents like these (sexually harassing situations), I never keep them a secret. I tell others that something like this has happened to me. Sometimes I even tell the name of the person. I tell them be careful, that he made a proposal like this.

Malani does not appear to be seeking emotional support (where she is expecting empathy and care) by narrating her experiences to other women, but, rather she is trying to provide information to them so that they can be careful of certain people and protect themselves. However, while providing this informational support, Malani is uncertain how the others will perceive her and her character.

They say 'really...did he say something like that?' But sometimes it is like this...they don't have what they say in their hearts. I don't know whether they think about me in a bad manner also like... 'She too goes with them (perpetrators) willingly, laughing and smiling'... I don't know whether they think like that.

This uncertainty of how the advice or support will be considered is one reason why women generally do not seek social support (Bingham \& Scherer 1993, Wijayatilake \& Zachariya 2000, Haspels et al. 2001, Chaiyavej \& Morash 2009). Despite this uncertaintly women appear to be sharing infromation in order to caution and advise others. 
Not So Silent: How Social Support is Given and Received in Dealing with Sexual Harassment in Sri Lankan Work-Places

Saumya (a 33-year-old married woman working as a development officer in a private financial institution) also stated how she advised her subordinates so that they could protect themselves.

I have about five people working under me. Four of them are girls. So I tell them also. 'He is like that. That one is like this'. I always tell them to be careful... I always tell them to come and tell me if something happens to them. Some of them are really very innocent... So I think the responsibility lies with me totally. If something were to happen to them I have to be responsible. So I try to protect them as much as possible. I always advise them about these things.

Here Saumya is providing informational support to her colleagues out of a sense of responsibility and kinship rather than friendship while she is cautions the subordinates about certain people.

Similarly Dhammi advises her friends:

Even now I advise the sisters (younger girls) in my hostel, this is how you should behave in front of males. Sometimes they may tell you something with a double meaning. But 'you' have to ignore them, pretend that you didn't understand it. Then they too would ignore it. If you go behind them saying you didn't understand it you can really get 'baited'.

Even though there does not appear to be total openness as with friends, in FG 4, the respondents stated how they talk about popular flirts and their behaviours in the organization when they get-together at work (mainly during lunch).

FG 4

Rasika: $\quad$ Yes. We discuss them in public sometimes.

Namali: $\quad$ At lunch mainly. We have a good laugh sometimes.

However, Rasika of FG 4 also stated in another instance how she does not like to share certain things in the open. Hence, more information was gathered about FG 4, which indicated these conversations they had (during breaks and lunch) were mainly about popular flirts and also when they were certain that they would not be reprimanded for these discussions. In other instances they did not discuss these in the open fearing reprisals if the perpetrators 


\section{NSBM Journal of Management}

Vol. 1, No. 2, July-December, 2015

got to know that their behaviours were discussed. They did not appear to share their own experiences of sexual harassment with their co-workers at all. As also discussed above under emotional support, it is apparent that among friends sharing personal experiences of sexual harassment is open and common, while among those who are not friends such sharing is not common. Overall, information sharing is selective, where trust about each other appears to play an important role.

This informational support is also seen to exist for new female employees who join an organization. For instance, Pamela, (a 26-year-old, unmarried clerk working for a government educational institution) stated:

The other female clerk told me to be careful of certain lecturers. She said that she has had a lot of problems. She said that some lecturers come on to her. She said to mind my own business and wait and then it would be ok. She said that when she was working on the computer they come too near and brush against her when working with her.

Thushy, a 32-year-old married accountant working for a private company reminisced about her experiences, when she first joined the company a few years back:

I was advised not to go to the stores alone where labourers were working. I was told that the stores were not a good place for a girl to go alone.

But as FG 2 below indicates, generally there are certain characteristics of the new employees that are looked into before the warning. For example, the existing employees would warn the newcomers if they are thought to be innocent, not aware of the flirts' intentions or when the newcomers become friends.

\section{FG 2}

Interviewer: $\quad$ With whom do you discuss these different incidents and people? With everybody or ...

\section{Waruni and}

Thanu:

No, no, not with everybody. Only with friends.

Malka: $\quad$ Only with department people. They told me about different people when I joined and told me to be careful.

Thushari: $\quad$ Not only for friendship. When they feel that she is innocent they tell. 
Not So Silent: How Social Support is Given and Received in Dealing with Sexual Harassment in Sri Lankan Work-Places

Hasini: $\quad$ Certain people are very popular. Everybody knows. The first day at my job, my manager told me about various people. My manger is a female. She told me to keep my distance with certain people...

Tulakshi: $\quad$ Because she is a female.

Previous studies have identified support receivers' characteristics such as personality and age as well as the situation such as expectations and demands of work and family, as playing a role in the acceptance and provision of support (Shinn, Lehmann \& Wong 1984, Hupcey 1998). It is also said that more support is given if the situation is not a result of the recipient's action but is a direct result of the recipients action (Hupcey 1998). While the current findings did not indicate the precise factors identified in previous studies, it did indicate how the charachteristics of women and the siatuational factors (whether the situation is a result of the victim) contribute to the provision of infomational support.

There were also very few instances where the superiors too had provided informational support by mainly advising the respondents about how to interact with males or how to be careful of certain people.

Daya, who is a 50-year-old teacher working in a private educational institute, stated how her principal advised her about protecting herself.

The principal had advised me about interacting with males and all.

Saumya also mentioned how one of her superiors provided informational support to her about sexual harassment when she first joined her current organization.

When I was new, he once asked me to come to his office room and told me, 'Saumya, you know I don't talk to everybody, but I need to tell you this. There is a group of people here who don't know how to behave. Their whole family lives have been messed up by their behaviours. So you have to be careful in dealing with these people and you have to protect yourself. Identify these people and interact with them accordingly. Don't go to be too friendly with people. Keep your distance from them and keep to your limits. There are lots of filthy people here. Be careful..

In many of the instances recounted by respondents, the source of informational support has been women friends, women co-workers, or women superiors. Yet, the above instance 


\section{NSBM Journal of Management}

Vol. 1, No. 2, July-December, 2015

indicates how a male superior in the office had provided informational support to respondents, so that they could protect themselves against sexual harassment. Similarly there were a very few instances where the male co-workers too had provided informational support to women at work.

Nimmi (29-year-old unmarried lecturer in a government university):

When we first joined, XX sir said that we should behave like this (how to behave in the work setting), that this place is like this...

In addition to this informational support received and given among friends and co-workers, some respondents stated how even their family members provided them informational support by advising them about certain people at work, even though they do not work in the same office. These family members get to know about these colleagues through what the respondents tell them or by meeting them at different events (e.g. office gatherings, trips, get-togethers). Through these interactions or information they have about certain people at work, they advise respondents against these people. Such advice from husbands appears to be rather frequent. This finding is consistent with Gottlieb and Bergens (2010) assertions that it is common for men to provide advice and recommendations to their wives, when wives reveal an emotionally disturbing experience.

Sarani (34- year-old, married senior executive working in a private bank) mentioned how her husband would advise her against certain people she worked with:

My husband also sometimes tell me to be careful of certain people, when he knows them or they sometimes get the feel, so then he tells me.

Also, unlike for emotional support discussed above, informational support received by parents was more general and was more about protecting themselves and their virtues as women in society rather than against specific people or acts related to sexual harassment at the workplace.

Whether this informational support received by respondents was actually effective, i.e., whether the respondents made use of the informational support they received, was also explored. In many instances the respondents had protected themselves against these perpetrators by being careful with them when dealing with them or by avoiding or minimizing their dealings with these perpetrators after the informational support. (This is discussed in detail under appraisal support). 
Not So Silent: How Social Support is Given and Received in Dealing with Sexual Harassment in Sri Lankan Work-Places

Yet, there were also instances narrated by respondents where informational support was either not believed by the recipient or where it had led to negative outcomes for the support givers.

Shyamalee (34-year-old married banking executive):

Sometimes we don't know whether it (the advice given against certain people) is true. Some might spread these stories about people for revenge.

Nimmi stated of an instance where the informational support given had created issues for her:

Once, it really blew out and now it has become a problem. Once we told another peer (girl) to be careful of this person and she had gone and told him and now it has become a problem.

Bowling and Beehr (2006), citing Skjorshammer and Hofoss, state how social support can lead to conflicts with family members and friends. Yet, here, informational support had not led to conflicts within the support networks, but rather conflicts had occurred outside this network with others, indicating negative effects that can arise due to informational support. As Shinn, Lehmann and Wong (1984) state the well-intended support had 'backfired'.

Interviews and focus group discussions also indicated how this informational support had actually led to women making decisions as in instrumental support and appraised certain experiences leading to appraisal support as well. (This is discussed below in more detail under instrumental and appraisal support).

In summary, it was seen how social interactions at work is a source of information for women about what happens in organizations in terms of sexual harassment, norms about sexual harassment and sexual behaviours, whom to be careful of and how to protect themselves. This leads to informational support helping respondents protect themselves and deal with sexual harassment instances at the workplace.

\section{Instrumental Support}

Instrumental support involves protective behaviour through the provision of tangible (such as financial aid) and intangible (help them do their work, take care of them) acts that directly assist others in need (House 1981). Instrumental support too was seen to be present in different forms for respondents in the current study with regard to sexual harassment. In some instances friends, co-workers or family appeared to provide instrumental support, 


\section{NSBM Journal of Management}

Vol. 1, No. 2, July-December, 2015

especially to deal with the experiences, at the request of the victim or sometimes with the support givers own volition.

Nilukshi (28-year-old, married, bank employee) mentioned how her female colleagues were harassed and how she stood up for them. As she stated,

...They (other females in her department) are afraid. Mainly because they are not confirmed, they won't speak up. So when I couldn't bear it up any longer I went and told the manager...

Here it is apparent how Nilukahi had taken it upon herself to protect and help the younger and junior colleagues and hence provided instrumental support. Kumudi (23-year-old, unmarried, junior executive of a financial institution) also recounted instances where she had obtained instrumental support from her co-workers.

And I came and told this 'aiya' (older male co-worker). He was my executive. I was his coordinator. He told me, 'Nangi (younger sister) the only advice I would give you is not to show embarrassment in front of any man. If you have to say something just tell it straightaway. If you show embarrassment you will never be able to get your work done and they would make fun of you too. That really got in to my mind.

A few other respondents stated how they had got the support of co-workers or friends working in the company when they were asked to stay after working hours to finish some work and when they suspected ulterior motives for these requests made by superiors. In these instances they got a friend or a co-worker to stay after work with them to finish the work, so that they were not alone.

Shyamalee stated:

I somehow get another person also to stay with me.

Similar methods employed by victims in dealing with sexual harassment are mentioned by Dansky and Kilpatrick (1997), where bringing a friend to a meeting to avoid harassment is highlighted.

McDonald et al. (2010) talks about corroboration in the face of sexual harassment, where victims would seek support also from co-workers who had experienced similar behaviours or witnesses. Seeking support from witnesses was seen when the victims sought formal 
Not So Silent: How Social Support is Given and Received in Dealing with Sexual Harassment in Sri Lankan Work-Places

redress, rather than informal redress. However, the respondents in the present study did not reveal instances where they had specifically sought co-workers who had experienced similar behaviour or witneeses to such behaviour. Rather, they expressed seeking support generally from co-workers.

Tanya's (23-year-old banking trainee) experiences indicate how her co-workers had encouraged her to make formal complaints regarding her experiences of sexual harassment:

They (other co-workers) have said to complain.

It is also interesting to note that when previous studies have indicated how victims are discouraged by others from taking action against harassment, the above statement of Tanya indicates an instance where she had been actually encouraged to seek formal redress. In another instance, Rupika stated how when the boss had attempted to kiss her and embrace her forcibly, her husband had advised her to call the police. It was Rupika who refused as she did not want to create more issues.

In another instance, Rupika stated how she had sought support from her husband to ensure that she did not face unwanted sexual behaviours. Rupika said that she got her husband to accompany her when she had to visit certain government organizations to get things done related to her job (such as transfers, leave matters, etc.).

When you go to meet them (certain people with the proclivity to harass, government officials) with your husband they do not behave like that (in a sexually harassing manner). In these instances I always take my husband with me. Then everything is ok.

Demonstrating another instance where instrumental support was provided, Saumya shared her experiences at an earlier workplace, where she had perceived her superior's behaviour towards her as harassing, and after several incidents, the superior had bellowed at her. Saumya had immediately called one of her brothers and related the incident. He had immediately come to her aid.

He came near the hotel, he couldn't come inside... and said 'You come out, you resign from the place. But don't come without doing anything. You come out only after striking him' 


\section{NSBM Journal of Management}

Vol. 1, No. 2, July-December, 2015

Saumya's fiancé too had been working in the same workplace during this time and while Saumya had not sought help from him regarding this matter, he too had got involved in the incident at one time when the superior had bad mouthed Saumya in front of him.

After this incident he had asked my fiancé to come and started to tell him 'Your girlfriend has a very bad mouth...' And then my fiancé who is a technician there, had taken out a tool from his pocket and had held it to his neck and told him 'don't say another word or else I will kill you' and he had just kept quiet.

With the support of family and her partner, Saumya was able to deal with the issue. Whether this support was effective or not cannot be directly established but Saumya perceived this support she got as positive.

It was also seen that when respondents went mainly to mothers and female friends for emotional support, they sought the aid of fathers or male siblings when they needed instrumental support.

Jane (26-year-old, unmarried, IT project manager):

I specially think security-wise we need a man's support and we cannot have that alone in the environment we have right now. So it is always good to have a male behind you.

Kalpi (26-year-old, unmarried insurance agent, working for an insurance company):

Having a brother means we don't have to fear for anything. There has to be a male sibling in a family. Even if he doesn't do anything he has to be there. We won't have to be frightened of anything then.

Many of the instances of instrumental support the respondents related involved co-workers and family members. However, it is said that social support from friends helps the victims more than the support from family (Livingston 1982 cited in Pina \& Gannon 2012). Yet, this fact was not revealed in the current study.

Social support is identified in sexual harassment research as an assertive response (Magley 2002) and also as the most common coping mechanism in certain cultures such as Hong Kong (Chan, Tang, \& Chan 1999). However, it is also said that family and friends may withdraw from social support if the culprit failed to take action to end the harassment or due to fear of retaliation by the company (Rospenda, Richman, \& Shannon 2006). Nevertheless, 
Not So Silent: How Social Support is Given and Received in Dealing with Sexual Harassment in Sri Lankan Work-Places

the respondents of the study did not indicate instances where the family members or even co-workers had refused to help or had withdrawn from helping the respondents in the face of sexual harassment.

\section{Appraisal Support}

Another supportive behaviour evident from the interviews and focus group discussions was sharing of information leading to self-evaluation, appraisal and reappraisal of situations and information. House (1981) and other scholars of social support, term this supportive behaviour as 'appraisal behaviour'.

It was thus seen how respondents' understanding and judgement of the concept of sexual harassment, their own experiences as well as their reactions to sexual harassment were either confirmed or altered due to different sources of information they received from others. Bingham (1994) and later other scholors too have emphasized the creation and shaping of knowledge and understanding of sexual harassment through communciation (Dougherty 1999, Miranda \& Saunders 2003, Denissen 2010) and how social support shape women's definitions of sexual harassment (Handy 2006). As Dougherty (1999) affirms, 'Although most men and most women are not personally involved in a harassing situation, they still actively construct what it means to be sexually harassed. As a result, the social construction of sexual harassment occurs not only during talk about sexually harassing experiences but also during talk about the possibility of sexually harassing experiences' (p. 438).

Focus group discussions specifically showed the manner in which the respondents reacted to others' comments, drew on others' beliefs, asked questions and built on others' ideas, and ultimately altered their appraisals of and understanding of sexual harassment.

The respondents started to remember many incidents of a harassing nature as they went deep into the discussions. Sometimes, even the incidents they did not think of as sexual harassment earlier were later related as such, when others narrated a similar incident. For example, those who stated that sexual harassment for them was more serious acts of a sexual nature at the beginning of the discussion, later went on to explain how even various other less serious behaviours of a sexual nature could make a person uncomfortable or feel harassed. Thushari was one such respondent who was under the impression that sexual harassment at the workplace was more quid pro quo harassment (threatening negative consequences or promising benefits in exchange for sexual favours). But then later on, when others started narrating different experiences they had had and had made them uncomfortable, she too started identifying other behaviours such as touching, pinching, and comments as harassing. 


\section{NSBM Journal of Management}

Vol. 1, No. 2, July-December, 2015

It is found in sexual harassment research that when people are cued or when they become aware of the issue, they tend to identify more behaviours as sexual harassment (JaschikHerman \& Fisk 1995, Brewis 2001, Wiener et al. 2005, Pickerill, Jackson, \& Newman 2006). Being cued or gaining awareness about the issue through listening to others and through discussions related to sexual harassment can be the reason why respondents of the focus group started appraising what sexual harassment actually meant.

This conversation which took place in FG 2 clearly signifies how the meaning was coconstructed by the respondents:

Thushari: $\quad$ We always keep things (experiences of a sexual nature) in the back of our head without bringing them to the open.

Hasini: $\quad$ I didn't think that there were such things in my office. But only when I started talking about them did I find out that they are real.

Thanu: $\quad$ Yes. Like that incident... (referring to an incident they discussed previously during the focus group). I completely forgot about it until we started talking about them.

Waruni: $\quad$ Can't we take overloading you with work as sexual harassment?...

Thushari: $\quad$ What do you mean?

Waruni: $\quad$ Like giving more work. Like an unbearable work load.

Hasina: $\quad$ Is it sexual harassment? I am not very sure.

Waruni: I don't know. For me, yes. Like if you are given the work of a male. The work only a male can do being given to a female. I think, is sexual harassment.

Thushari: $\quad \quad \quad Y o u$ mean giving a man's work to a woman?

Waruni: $\quad$ Yes.

Thushari: $\quad$ Well... then maybe it is. But I think if you are given more work because you didn't agree to something he said, then maybe.

Similarly, it was seen how respondents also appraised or reappraised the behaviour of certain people (office flirts/ office Romeos), when they were warned about these people earlier by others such as co-workers (This was discussed in detail under informational support). After been warned respondents started seeing the behaviours of such people as harassing, where 
Not So Silent: How Social Support is Given and Received in Dealing with Sexual Harassment in Sri Lankan Work-Places

the same behaviour might not have been seen as harassing if not for the warning or the discussions that took place regarding the person.

\section{FG 2}

Thanu: ...I didn't take any notice of these (some unwanted attention she experienced). Then some said that he talks about me a lot and for me to be careful. Then I was very stern with him and avoided him...

Thushari: $\quad$..Yes. When I first joined the others told me not to deal with a particular male teacher... Then I deliberately kept my distance from him.

As respondents hear more stories about the said person, they appraised their experiences as sexual harassment. In another instance at the FG 2, Thanu stated:

...We talk about that man always. We hear different past stories about him. People tell different stories. And now we are all very careful of him.

FG 1 also talked about a known flirt in their organization and how even normal behaviour of this person is now considered as harassing after getting to know about his manners.

Mangala: $\quad$ Now it would be sexual harassment, even if X (harasser) asked us to come to his room for some office work.

Sansala: $\quad$ Once we had to go to him to collect money for something. We were so scared to go into his room like we (Sansala and Kimali) were holding hands tightly in front of the room almost shivering.

Kimali: $\quad$ Yes. even before going into the room.

This revelation too clearly indicated how the behaviour of certain people would be appraised as sexual harassment based on discussions about the person within the social networks.

Sometimes respondents, such as Kalpi, had sought appraisal support from others about how they had handled instances of sexual harassment. Kalpi, who had a customer making suggestive comments and unwanted invitations to go out with her to finalize a business deal, had refused his invitations and had lost the deal. Kalpi had sought appraisal support from her mother as well as superiors where they had confirmed Kalpi's reactions. This made Kalpi more confident about herself and her reactions. 


\section{NSBM Journal of Management}

Vol. 1, No. 2, July-December, 2015

Kalpi:

I told him that we don't have to go there to sign a deal and that we can do it in the company and I refused. When I told this to Amma she told me not to go, like she is really scared of those. Anyway, when I refused he said that he would cancel the deal. And I told him fine! I then told this to my manager and even he agreed that it is not the thing to do.

This is also known as the affirmative support Kahn and Antonucci, 1980 (as cited by Langford et al. 1997) refer to under appraisal support. Affirmative support is the expression that affirms the appropriateness of an act or statement made by another.

It is noteworthy how research that has explored the appraisal of sexual harassment instances or sexual conduct have failed to consider this social support in the form of information giving and receiving leading to evaluation and re-evaluation of situations (Fitzgerald et al. 1997, Langhout et al. 2005). Generally these earlier studies have considered different factors such as frequency of the conduct, intensity of a conduct, prior experiences, perpetrator characteristics, victim's personality and organizational context as effecting how a individual would appraise a sexual conduct. Yet, the discussions above indicates how appraisal support too would play a role in this appraisal, evaluation (Berdahl \& Aquino 2009), judgment (O’Connor et al. 2004), or perceptions and attitudes towards sexual harassment (Barr 1993, Dougherty et al.1996, Foulis \& McCabe 1997, Bursik \& Gefter 2011) or a situation.

\section{Conclusion}

While previous studies have indicated how sexual harassment is an individualized experience which isolates the victim (Clair, 1993 as cited in Dougherty 1999), it was seen how the respondents of the present study frequently engaged in social interaction and dialogue related to sexual harassment thus making it non-individualized. Through these interactions and dialogues which take place with different social networks, women receive and give social support.

Mainly women were found to seek or gain support from family members (such as parents, siblings, and husbands), partners, friends, co-workers and/or supervisors. Primarily women would share information related to their experiences with friends and family, seeking and receiving empathy and care, leading to emotional support. With regard to emotional support, women do not appear to approach co-workers much. Women also provide informational support by providing advice, guidance, suggestions, or useful information about sexual 
Not So Silent: How Social Support is Given and Received in Dealing with Sexual Harassment in Sri Lankan Work-Places

harassment and mainly cautioning and advising others about such instances and specific people to be careful of. This appears to be the most common and frequent type of support among the respondents. Friends and co-workers were found to be providing informational support more, with primarily women being the most common source of support. Instrumental support was found to be received predominantly from family, friends and co-workers. Finally, through these interactions, women appraise and evaluate their experiences of sexual harassment as well as re-define their understanding of sexual harassment in certain instances, which is known as appraisal support. These social interactions and support help women overcome their sense of powerlessness and anxiety in the face of sexual harassment and cope with sexual harassment more effectively.

As also shown by House (1981), these different types of social supports were not always exclusive, and were occasionally interrelated and connected. For example, there were instances where informational support such as advice and cautioning about flirts in the organizations received by respondents also led them to appraise their experiences and interactions with these individuals differently.

Further, even though prior research presents how women can be criticized or scolded for their experinces of sexual harassment (Wijayatilake \& Zachariya 2000, Haspels et al. 2001), the current study did not indicate respondents facing such situations when seeking social support. This can be due to respondents carefully (knowlingly or unknowingly) choosing whom to share information with or seek support from, depending on the situation and the type of support needed. It was seen how friends and family members were mainly supportive without being condemnatory. Moreover, the fact that in certain instances, such as with informational support, the opportunity to be critical or condemnatory was less, as it was mainly about advice and cautioning women to protect themselves. In addition, advising and cautioning others can also be a machanism women employ to project themselves as virtuous and respectable (Adikaram 2014).

Further, it was noted that although social support can be given for a variety of reasons such as social obligation and future reciprocity (Hupcey 1998), the current study did not indicate instances where the support providers had provided support grudgingly as an obligation or where the recipient did not feel positive about the support. Respondents actually appeared to give and receive these various types of support happily and voluntarily, especially informational support and appraisal support. 
These findings are somewhat contrary to the findings on attitudes towards sexual harassment in collectivist cultures or non-western cultures (Sigal et al. 2005) such as Sri Lanka. It is also said that in collectivist cultures public discussions of sexual harassment are rare (Sigal et al. 2005) and that people are more ready to accuse the victim and hold her more responsibile the victim for the harassment that had occurred. Collectivist cultures are also said to be concerned more about preserving harmony in society and to value the needs of society rather than individual rights. Hence, with these attitudes and perceptions, it is found that in collectivist cultures people tend to provide less support and understanding to victims of sexual harassment. Further, prior studies have indicated how observers tend to blame the victim and excuse the harasser for sexual harassment due to their internalized societal perceptions about proper dress for women, and male superiority in society ( $\mathrm{Ng} \&$ Othman 2002, Adikaram 2014). However, contrary to these earlier findings, the current study indicated how people do tend to support victims and women prone to sexual harassment in numerous ways by showing empathy, understanding and sharing helpful information. Further, maybe due to this very collectivist culture, women and sometimes men appear to create a safety net for others through frequent and common advice and cautioning about flirts and situations of sexual harassmsnet in organizations. In conclusion, it can be seen how social support theory contributes to a deeper understanding of the manner women typically seek support and aid of various types from different social networks.

\section{Limitations of the Study}

Although I was able to explore many instances of how silence and secrecy related to sexual harassment at workpalces are broken. Due to the very nature of the issue and the cultural norms that discourage women from openly discussing such issues in the open (Sigal et al. 2005, Adikaram In press), the respodnents might have selectively shared their experiences and perceptions. Moreover, the respondents did not reveal many instances where they were condemned or criticized for sharing information or seeking social support. This too can be due to the respondents selectively sharing information, in order to project an image of respectability or uprightness.

\section{Implications for Managers}

While social support in its multiple forms will not be the only or the main panacea for sexual harassment, it certainly can be used as a means of handling sexual harassment amidst the failures of many other strategies employed to combat the issue. or at least to eliminate stress as a result of sexual harassment. 
Not So Silent: How Social Support is Given and Received in Dealing with Sexual Harassment in Sri Lankan Work-Places

As the research indicates, if the social supports are effective, it removes the need for more formal support (House 1981). In a context where more formal strategies such as implementation of policies and legislation not having the expected outcome (McDonald et al. 2010), organizations should explore the possibilities of promoting social support in organizations as a strategy for combating and dealing with sexual harassment. The importance of social support can be highlighted in company training programmes on sexual harassment '...by acknowledging that employees can both exercise concern for the workgroup and respond assertively to sexual harassment and by engaging coworkers and supervisors in providing support...' (Chaiyavej \& Morash 2009, p. 79). Organizations should also empower women to handle sexual harassment by developing and maintaining social support systems. Further, organizations must explore how social support can be increased (Demirtas, Ozdevecioglu \& Capar 2015).

Organizations should also consider other sources of social support for women employees. While the current study did not indicate respodnents approaching other sources such as trade unions and counsellors for support in instaces of sexual harassmnet, companies can explore the possibility of popularising these other sources of social support as well, as women may not be seeking these other sources due to lack of access (Wear, Aultman \& Borgers 2007) or awarenss.

\section{Future Research}

Furture research should continue to examine this concept of social support in sexual harassment by studying other types of social support women receive as well as the costs and benefits of social support and their negative impact. Moreover, studies can investigate the specific contexts and personal charachteristics of the receipients of social support as well as how women decide whether support is given or received.

\section{References}

Adikaram, AS 2014, “"Good women" and "bad women": How socialization of gendered behavioural norms influences Sri Lankan working women's interpretation of sexual harassment at workplaces', South Asian Journal of Human Resource Management, vol. 1, no.1, pp. 45-65.

Adikaram, AS (in press ), "“Unwanted" and "bad", but not "sexual": Non-labeling of sexual harassment by Sri Lankan working women', Personnel Review.

Barr, PA 1993, 'Perceptions of sexual harassment', Sociological Inquiry, vol. 63, no. 4, pp. 460-470.

Barrera Jr, M 1986, 'Distinctions between social support concepts, measures, and models', American Journal of Community Psychology, vol. 14, no. 4, pp. 413-445. 


\section{NSBM Journal of Management}

Vol. 1, No. 2, July-December, 2015

Berdahl, JL \& Aquino, K 2009, 'Sexual behavior at work: fun or folly?' Journal of Applied Psychology, vol. 94 , no. 1, p. 34 .

Bingham, SG \& Scherer, LL 1993, 'Factors associated with responses to sexual harassment and satisfaction with the outcome', Sex Roles, vol. 29, nos. 3-4, pp. 239-269.

Bingham, SG 1994, 'Introduction: Framing sexual harassment-defining a discursive focus of study. In S.G. Bingham (ed), Conceptualizing sexual harassment as discursive practice (pp. 1-14), CT: Praege, Westport.

Bowling, NA \& Beehr, TA 2006, 'Workplace harassment from the victim's perspective: a theoretical model and meta-aalysis, Journal of Applied Psychology, vol. 91. no. 5, pp. 998-1012.

Brewis, J 2001, 'Foucault, politics and organizations: (re)-constructing sexual harassment'. Gender, Work and Organization, vol. 8, no. 1, pp. 37-60.

Brough, P \& Frame, R 2004, 'Predicting police job satisfaction and turnover intentions: the role of social support and police organisational variables', New Zealand Journal of Psychology, vol. 33, no. 1 , pp. 8-16.

Brough, P \& Pears, J 2005, 'Evaluating the influence of the type of social support on job satisfaction and work-related psychological well-being', International Journal of Organizational Behavior, vol. 8, no. 2, pp. 472-485

Bursik, K \& Gefter, J 2011, 'Still stable after all these years: perceptions of sexual harassment in academic contexts', The Journal of Social Psychology, vol. 151, no. 3, pp. 331-349.

Cense, M \& Brackenridge, C 2001, 'Temporal and developmental risk factors in sexual harassment and abuse in sport,' European Physical Education Review, vol. 7, no.1, pp. 61-79.

Chaiyavej, S \& Morash, M 2009, 'Reasons for policewomen's assertive and passive reactions to sexual harassment.' Police Quarterly, vol. 12, no. 1, pp. 63-85.

Chamberlain, L J Crowley, M, Tope, D \& Hodson, R 2008, 'Sexual harassment in the organizational context', Work and Occupations, vol 35, no. 3, pp. 262-295.

Chan, DKS, Tang, CSK \& Chan, W 1999, 'Sexual Harassment: a preliminary analysis of its effects on Hong Kong Chinese women in the workplace and academia', Psychology of Women Quarterly, vol. 23, no. 4, pp. 661-672.

Charmaz, K 2003, 'Grounded theory: objectivist and constructivist methods', in NK Denzin \& YS Lincoln (eds), Strategies of qualitative inquiry, 2nd edn, Thousand Oaks, CA: Sage.

Chamaz, K 2005, 'Grounded theory in the 21st century: applications for advancing social justice studies', in NK Denzin \& YS Lincoln (eds), The sage book of qualitative research, 3rd edn, Thousand Oaks, CA: Sage.

Clair, RP 1993, 'The bureaucratization, commodification and privatization of sexual harassment through institutional discourse: a study of the big ten universities', Management Communication Quarterly, vol. 7, no. 2, pp. 123-157.

Cohen, S \& Wills, TA 1985, 'Stress, social support, and the buffering hypothesis', Psychological Bulletin, vol. 98, no. 2, pp. 310-357. 
Not So Silent: How Social Support is Given and Received in Dealing with Sexual Harassment in Sri Lankan Work-Places

Cooke, BD, Rossmann, MM, McCubbin, HI \& Patterson, JM 1988, 'Examining the definition and assessment of social support: A resource for individuals and families', Family Relations, vol. 37, no. 2, pp. 211-216.

Copeland, AP \& Norell, SK 2002, 'Spousal adjustment on international assignments: the role of social support', International Journal of Intercultural Relations, vol. 26, no. 2, pp. 255-272.

Cortina, LM \& Wasti, AS 2005, 'Profiles in coping: Responses to sexual harassment across persons, organizations and cultures', Journal of Applied Psychology, vol. 90, no. 1, pp. 182-192.

Dansky, BS \& Kilpatrick, DG 1997, Effects of sexual harassment, in WO donohue, sexual harassment: theory, research and treatment, Allyn \& Bacon, Boston, London.

De Judicibus, M \& McCabe, MP 2001, 'Blaming the target of sexual harassment: impact of gender role, sexist attitudes, and work roles', Sex Roles, vol. 44, no. 7, pp.401-417

Demirtas, O, Ozdevecioglu, M \& Capar, N 2015, 'The relationship between cognitive emotion regulation and job stress: moderating the role of social suppor', Asian Social Science, vol. 11, no. 12, pp. 168-173.

Denissen, AM 2010, Crossing the line: How women in the building trades interpret and respond to sexual conduct at work. Journal of Contemporary Ethnography, vol. 39, no. 3, pp. 297-327.

Diekmann, KA, Walker, SDS, Galinsky, AD \& Tenbrunsel, AE 2013, 'Double victimization in the workplace: why observers condemn passive victims of sexual harassmen', Organization Science, vol. 24, no. 2, pp. 614-628.

Dougherty, SD 1999, 'Dialogue through standpoint: understanding women's and men's standpoint of sexual harassment', Management Communication Quarterly, vol. 12, no. 3, pp. 436-468.

Dougherty, TW, Turban, DB, Olson, DE, Dwyer, PD \& Lapreze, MW 1996, 'Factors affecting perceptions of workplace sexual harassment', Journal of Organizational Behavior, vol. 17, no. 5, pp. 489-501.

Fitzgerald, LF \& Ormerod, AJ 1993, 'Breaking silence: the sexual harassment of women in academia and the workplace', in Denmark, Florence L \& Paludi, Michele A (eds), Psychology of women: a handbook of issues and theories, Greenwood Press/Greenwood Publishing Group, Westport, CT, US.

Fitzgerald, LF, Swan, S \& Fischer, K 1995, 'Why didn't she just report him? The psychological and legal implications of women's responses to sexual harassment', Journal of Social Issues, vol. 51, no. 1 , pp. 117-138.

Fitzgerald, LF, Swan, S \& Magley, VJ 1997, 'But was it really sexual harassment?: Legal, behavioural, and psychological definitions of the workplace victimization of women in WO'Donohue (eds), Sexual harassment: theory, research and treatment (pp. 29-49), Allyn and Bacon, Boston, London.

Foucault, M 1990, The history of sexuality: an introduction, vol.1, Random House, New York.

Foulis, D \& McCabe, MP 1997, 'Sexual harassment: factors affecting attitudes and perceptions', Sex Roles, vol. 37, nos. 9-10, pp. 773-798.

Gottlieb, BH \& Bergen, AE 2010, 'Social support concepts and measures', Journal of Psychosomatic Research, vol. 69, no. 5, pp. 511-520. 


\section{NSBM Journal of Management}

Vol. 1, No. 2, July-December, 2015

Gutek, BA \& Koss, MP 1993, 'Changed women and changed organizations: consequences of and coping with sexual harassment', Journal of Vocational Behavior, vol. 42, pp. 28-48.

Handy, J 2006, 'Sexual harassment in small-town New Zealand: a qualitative study of three contrasting organizations', Gender, Work and Organization, vol. 13, no. 1, pp.1-24.

Haspels, N, Kasim, ZM, Thomas, C, \& McCann, D 2001, Action against sexual harassment at work in Asia and the Pacific, International Labor Office, Bangkok.

Heaphy, DE \& Dutton, JE 2008, 'Positive social interactions and the human body at work: linking organizations and physiology', Journal of Management Review, vol. 33, no. 1, pp. 137-162.

Hotelling, K 1991, 'Sexual harassment: a problem shielded by silence', Journal of Counseling \& Development, vol. 69, no. 6, pp. 497-501.

House, JS 1981, Work stress and social support, Addison-Wesley Publishing, London \& Sydney.

Hupcey, JE 1998, 'Clarifying the social support theory-research linkage', Journal of Advanced Nursing, vol. 27 , pp. 1231-1241.

Jang, EH \& Lee, M 2013, 'Korean high school students' perceptions of sexual harassment: the effects of victim's clothing, behavior, and respondent's gender', International Journal of Human Ecology, vol. 14 , no. 1, pp. 57-69.

Jaschik-Herman, ML \& Fisk, A 1995, 'Women's perceptions and labeling of sexual harassment in academia before and after the Hill-Thomas hearing', Sex Roles: A Journal of Research, vol. 33, nos. 5-6, pp. 439-446.

Khan, ME \& Manderson, L 1992, 'Focus groups in tropical diseases research', Health Policy and Planning, vol. 7, no. 1, pp. 56-66.

King, CS 1995, 'Ending the silent conspiracy: sexual harassment in nursing', Nursing Administration Quarterly, vol. 19, no. 2, pp. 48-55.

Kirby, S 1995, 'Not in my backyard: sexual harassment and abuse in sport', Canadian Woman Studies, vol. 15 , no. 4 , pp. $65-72$.

Lakey, B \& Cohen, S 2000, 'Social support theory and measurement' in S Cohen, LG Underwood and BH Gottlieb (eds), Social support measurement and intervention: a guide for health and social scientists, pp. 29-52, Oxford University Press, Oxford, New York.

Langford, CP, Bowsher, J, Maloney, JP \& Lillis, PP 1997, 'Social support: a concept analysis', Journal of Advanced Nursing, vol. 25, pp. 95-100.

Langhout, R D, Bergman, ME, Cortina, LM, Fitzgerald, LF, Drasgow, F \& Williams, JH 2005, 'Sexual harassment severity: assessing situational and personal determinants and outcomes', Journal of Applied Social Psychology, vol. 35, no. 5, pp. 975-1007.

Leavy, RL 1983, 'Social support and psycholgical disorder: a review', Journal of Community Psychology, vol. 11, pp. 3-21.

Magley, VJ 2002, 'Coping with sexual harassment: reconceptualizing women's resistance', Journal of Personality and Social Psychology, vol. 83, no. 4, pp. 930-946. 
Not So Silent: How Social Support is Given and Received in Dealing with Sexual Harassment in Sri Lankan Work-Places

Marks, S, Mountjoy, M, \& Marcus, M 2012, 'Sexual harassment and abuse in sport: the role of the team doctor’, British Journal of Sports Medicine, vol. 46, no. 13, pp. 905-908.

McDonald, P 2012, 'Workplace sexual harassment 30 years on: a review of the literature', International Journal of the Management Reviews, vol. 14, no. 1, pp. -17.

McDonald, P, Graham, T \& Martin, B 2010, 'Outrage management in cases of sexual harassment as revealed in judicial decisions', Psychology of Women Quarterly, vol. 34, pp. 165-180.

Md-Sidin, S, Sambasivan, M, \& Ismail, I 2010, 'Relationship between work-family conflict and quality of life: an investigation into the role of social support', Journal of Manageral Psychology, vol. 25, no.1, pp. $58-81$.

Miranda, SM \& Saunders, CS 2003, 'The social construction of meaning: an alternative perspective on information sharing', Information Systems Research, vol. 14, no. 1, pp. 87-107.

Ng, C \& Othamn, J 2002, 'Unwanted and unwelcome: sexual harassment in the Malaysian workplace', Gender, Technology and Development, vol. 6, no. 3, pp. 389-407.

O’Connor, M, Gutek, BA, Stockdale, M, Geer, TM \& Melancon, R 2004, 'Explaining sexual harassment judgments: looking beyond gender of the rater, Law and Human Behavior, vol. 28, no. 1, pp. 69.

Peirce, ER, Rosen, B \& Hiller, TB 1997, 'Breaking the silence: creating user-friendly sexual harassment policies', Employee Responsibilities and Rights Journal, vol. 10, no. 3, pp. 225-242.

Pickerill, JM, Jackson, RA \& Newman, MA 2006, Changing perceptions of sexual harassment in the federal workforce, 1987-1994, Law and Policy, vol. 28, no. 3, pp. 368-394.

Penal Code (Amendment) No. 22 of 1995.

Pina, A \& Gannon, TA 2012, 'An overview of the literature on antecedents, perceptions, and behavioural consequences of sexual harassment, Journal of Sexual Aggression, vol. 18, no. 2, pp. 209-232.

Reese, LA \& Lindenberge, KE 1997, Victimhood and the implementation of sexual harassment policy. Review of Public Personnel Administration, vol. 17, pp. 37- 57.

Rospenda, KM, Richman, JA \& Shannon, CA 2006, 'Patterns of workplace harassment, gender, and use of services: an update', Journal of Occupational Health Psychology, vol. 11, no. 4, pp. 379-393.

Rudman, LA, Borgida, E \& Robertson, BA 1995, 'Suffering in silence: procedural justice versus gender socialization issues in university sexual harassment grievance procedures', Basic and Applied Social Psychology, vol. 17, no. 4, pp. 519-541.

Sapana Pradhan-Malla, 'Violence against women: good practices in combating and eliminating violence against women', Forum for Women, Law and Development (FWLD), Nepal, 2005, Sexual harassment in the workplace in Asia, Vienna, Austria.

Schneider, KT, Swan, S \& Fitzgerald, LF 1997, 'Job-related and psychological effects of sexual harassment in the workplace: empirical evidence from two organizations', Journal of Applied Psychology, vol. 82, no. 3, p. 401.

Shinn, M, Lehmann, S \& Wong, NW 1984, ' Social interaction and social support', Journal of Social issues, vol. 40, no. 4, pp. 55-76. 


\section{NSBM Journal of Management}

Vol. 1, No. 2, July-December, 2015

Shupe, EI, Cortina, LM, Ramos, A, Fitzgerald, LF \& Salisbury, J 2002, 'The incidence and outcomes of sexual harassment among Hispanics and non-Hispanic white women: a comparison across levels of cultural affiliation', Psychology of Women Quarterly, vol. 26, no. 2, pp. 298-308.

Sigal, J, Gibbs, MS, Goodrich, C, Rashid, T, Anjum, A, Hsu, D, Perrino, CS, Boratav, HB, CarsonArenas, A, van Baarsen, B \& van der Pligt, J 2005. 'Cross-cultural reactions to academic sexual harassment: effects of individualist vs. collectivist culture and gender of participants', Sex Roles, vol. 52, nos. 3-4, pp.201-215.

Simoni, JM, Frick, PA \& Huang, B 2006, 'A longitudinal evaluation of a social support model of medication adherence among HIV-positive men and women in antiretroviral therapy', Health Psychology, vol. 25, no. 1, pp. 74-81.

Tambiah, Y 1996, 'Interrogatory silence: articulating female sexuality’, Options, no. 7, pp. 20-21.

Thoits, PA1986, 'Social support as coping assistance', Journal of Consulting and Clinical Psychology, vol. 54 , no. 4 , p. 416.

Wasti, AS \& Cortina, LM 2002, 'Coping in context: sociocultural determinants of responses to sexual harassment', Journal of Personality and Social Psychology, vol. 83, no. 2, pp. 394-405.

Wear, D, Aultman, J and Borgers, N 2007, 'Re-theorising sexual harassment in medical education: women students' perceptions at five US medical schools' Teaching and Learning in Medicine, vol. 19, pp. 20-29.

Weeks, EL, Boles, JM, Garbin, AP \& Blount, J 1986, 'The transformation of sexual harassment from a private trouble into a public issue', Sociological Inquiry, vol. 56, no. 4, pp. 432-455.

Wijayatilake, K \& Zachariya, F 2001, Sexual harassment at work: plantation sector, International Labor Organization, Colombo

Wiener, RL, Voss, AM, Winter, RJ, \& Arnot, L 2005, 'The more you see it, the more you know it: memory accessibility and sexual harassment judgments', Sex Roles: A Journal of Research, vol. 53, nos. 11-12, pp. 807-819. 